\title{
Diagnostic and assessment of specific and transversal competences in Chemistry studies in a distance education
}

\author{
program
}

\section{González-Gómez*, A. Gallego-Picó**, R.M. Garcinuño**, M.J. Morcillo**, J.S. Durand $^{* *}$, P. Fernández**}

* Department of Didactics of Experimental Sciences, Faculty of Education, University of Extremadura (UNEX), Cáceres (Spain)

** Department of Analytical Sciences, Faculty of Sciences, National University of Distance Education (UNED), Madrid (Spain)

\begin{abstract}
The current socioeconomic conditions require highly educated professional with new curricula requirements and new skills, professionals with initiative and abilities able to be adapted to different situations and contexts. Consequently, the university education system must ensure that students achieve competences that involve the combination of knowledge, attitudes and values that enable a qualified person to undertake the resolution of problems or able to evolve in a new professional or social context. To achieve this goal, universities must find and use the most suitable tools to adapt and create higher education programs to respond to the needs of today's society, tuning academic and professional profiles. On the other hand, there is a significant growth of enrolling students in distance education universities and several distance education programs are available in most universities. Thus, the aim of this communication is to share the results obtained during the development of a teaching innovation project, which assessed interdisciplinary, specific and transversal competences, by means of a post-task objective test, in the Chemistry undergraduate studies at the National University of Distance Education, (UNED) of Spain. The results of this study have allowed to the professors board to analyse and assess the competences acquired by the students, pointing out the main deficiencies to be solved by re-designing the teaching activities and methodologies to ensure a complete success.
\end{abstract}

Keywords: Blended learning; High Education; Formative assessment; Innovative pedagogical strategy

\section{Introduction}

In Europe, as a result of the Bologna Process the educational systems in all European countries have made a significant process of change. Society demands from the academia the production of a more knowledgeable workforce, improving employee onthe-job performance and solving organizational problems (Richey et al., 2001). In this context, some professional organizations have already addressed this challenge and define these professional competencies as required learning outcomes. In order to provide these requirements, universities have re-designed the curricula keeping the coherence between objective, competences and contents, teaching methodology, learning activities and assessment system. On the other hand, the European Higher Education System has being overhauled to guarantee more comparable, compatible, and coherent systems in European countries according to the directives established in the Bologna Process (van der Wende, 2000). This new education system prioritizes the learning of generic competencies that will allow the acquisition of more specific knowledge and skills needed in a specific field. And therefore, teaching material and methodologies need to be updated to ensure the development of interdisciplinary specific and transversal skills, and way to assess them. In online and blended learning, teachers also need to reconceptualise fundamental issues of teaching, learning and assessment in non-traditional spaces (Gikandi et al., 2011).

This communication is focused on online formative assessment in order to create learner and assessment learning environments (Pachler et al., 2010; Wang et al., 2008). 
The objective of this research is to assess the learning results of students of Chemistry Undergraduate Program at National University of Distance Education in terms on specific and transversal competencies, as well as to evaluate the learning achievements from students of two different subjects (Basic Chemistry and Advanced Analytical Chemistry). The student's feedbacks about the instructional methodology, teaching material and resources have been also evaluated. Data were collected during four year comparing different methodologies.

\section{Methods}

The study was carried out with students of the subject Advance Analytical Chemistry taught in the last year of the Chemistry Degree Program and students of the subject Basic Chemistry (pre-university students), both on the bases of distance education system. The student's participation in this study was not compulsory. Data were collected from 2006 to 2010 to Advance Analytical Chemistry students, and during three years (2007-2010) to Basic Chemistry.

For this project, a Study Guide was designed with the aim of providing the student with a global overview of the subject contents, the knowledge to be learnt and more important highlighting the competencies (generic, specific and transversals) that students must develop within the subject. The Study Guide also includes basic instruction to guide the students in the learning process, content schedule and assessment calendar. In addition, the students are provided with interactive instructional material through the virtual campus, such as podcast, hot potatoes exercises, lectures presentation, conceptual maps and summaries of theoretical contents. Some of these activities were applied as a source of on-going feedback with the aim to improve teaching and learning and consequently as a tool of formative assessment. Formative assessment has been defined as a iterative processes of establishing what, how much and how well students are learning in relation to the learning goals and expected outcomes in order to inform tailored formative feedback and support further learning, a pedagogical strategy that is more productive when role is shared among the teacher, peers and the individual learner (Gikandi et al., 2011). In addition, e-learning environments including the complementary role of ICT in these activities (Pachler et al. 2010). Thus, the virtual classroom constitutes the main interaction scenario between professors and students and the collaborative work between students. On the other hand, asynchronous interaction allowed students to rethink and assess their own understanding of content before they posted their responses that facilitated reflective and self-assessment processes. Traditional exams also were present to evaluate specific skills.

Portfolio was other assessment tool employed to analyse the student's evolution in terms of learning contents and competences. Each student's portfolio includes selfassessment results, on-line and in-person test evaluations and students' opinion surveys. Portfolio was a multimodal tool in the learning processes (Dysthe et al., 2007).

The assessment indicators, used to evaluate the results were:

- Usability perception of the provided teaching resources and instructional methodology 
- Learning achievements

- Students satisfaction

- Professor perception and satisfaction

The transversal competencies were assessed by means of an objective on-line diagnostic test developed by the Institute of Knowledge Engineering (Instituto de Ingeniería del Conocimiento, ICC, Spain). More precisely, tools eValue and eCat were used (http://www.iic.uam.es/). These tests were only made with the Advance Analytical Chemistry students in the course 2008-2009.

\section{Results and Discussion}

During project achievement, a total of 60 students from a total of 183 enrolled in Advance Analytical Chemistry participated in this study. Only 63 students from a total of 1898 enrolled in Basic Chemistry participated in the project.

The age of the majority of students was over 30 years old (80\%) and female sex predominated, around $60 \%$. However, there is great variability in data for the different years.

Regarding the educational background, most of Advance Analytical Chemistry students already had another university degree and the participants were already workers of chemistry field companies. In last year of project, $54 \%$ of student already had another university degree and $46 \%$ were worked in chemistry companies. In the other subject, similar percentage of student was worked in chemistry field companies.

Finally, the vast majority reported to have medium or strong knowledge of how to use computer technologies.

\section{Assessment of specific competencies and learning achievements}

The results of the student's perception to the different assessment indicators are summarized in Table 1. In general terms, students have found useful or very useful all the teaching resources provided, and were specially useful to understand, analyse and study the subject contents. Conceptual Map tool only was implemented in Advances Chemistry subject.

Table 1. Student's perception of the different assessment indicators used in this study

\begin{tabular}{|c|c|c|c|c|c|}
\hline Assessment indicator & Parameter & $\begin{array}{c}\text { Little } \\
\text { useful }\end{array}$ & $\begin{array}{c}\text { Mild } \\
\text { Useful }\end{array}$ & Useful & $\begin{array}{c}\text { Very } \\
\text { useful }\end{array}$ \\
\hline \multirow{4}{*}{$\begin{array}{c}\text { Usability perception of the } \\
\text { provided teaching resources }\end{array}$} & Study Guide & $0 \%$ & $6 \%$ & $59 \%$ & $35 \%$ \\
\cline { 2 - 5 } & Lecture presentation & $0 \%$ & $0 \%$ & $75 \%$ & $25 \%$ \\
\cline { 2 - 5 } & Self-evaluation & $0 \%$ & $0 \%$ & $35 \%$ & $75 \%$ \\
\cline { 2 - 6 } & Conceptual Map & $6 \%$ & $0 \%$ & $88 \%$ & $6 \%$ \\
\cline { 2 - 6 } & $\begin{array}{c}\text { Debate virtual forums and } \\
\text { virtual classroom }\end{array}$ & $0 \%$ & $6 \%$ & $77 \%$ & $17 \%$ \\
\hline \multirow{3}{*}{$\begin{array}{c}\text { Usability perception of the new } \\
\text { instructional methodology }\end{array}$} & To plan the course & $0 \%$ & $40 \%$ & $60 \%$ & $0 \%$ \\
\cline { 2 - 6 } & To understand the contents & $0 \%$ & $10 \%$ & $80 \%$ & $10 \%$ \\
\cline { 2 - 6 } & To analyse the contents & $0 \%$ & $10 \%$ & $90 \%$ & $0 \%$ \\
\cline { 2 - 6 } & To study & $0 \%$ & $10 \%$ & $90 \%$ & $0 \%$ \\
\hline
\end{tabular}

In comparison, basic level subject had valued more positively the resources.

In Advanced Chemistry subject, regarding to the learning achievements, $63 \%$ of the students participating in this study passed the final exam. Considering the total number 
of students enrolled in the subject, 35\% passed the final exam, $18 \%$ did not reach the minimum score and $47 \%$ did not attend to the final exam. According to the survey results, students have found very positive the learning achievements and were very satisfied with the implemented instruction methodology.

\section{Assessment of transversal competencies}

Transversal competencies such as customer focus, leadership, flexibility to change, self-control, initiative, confidence, negotiation, communication and teamwork, were assessed. Results are summarized in Figure 1.

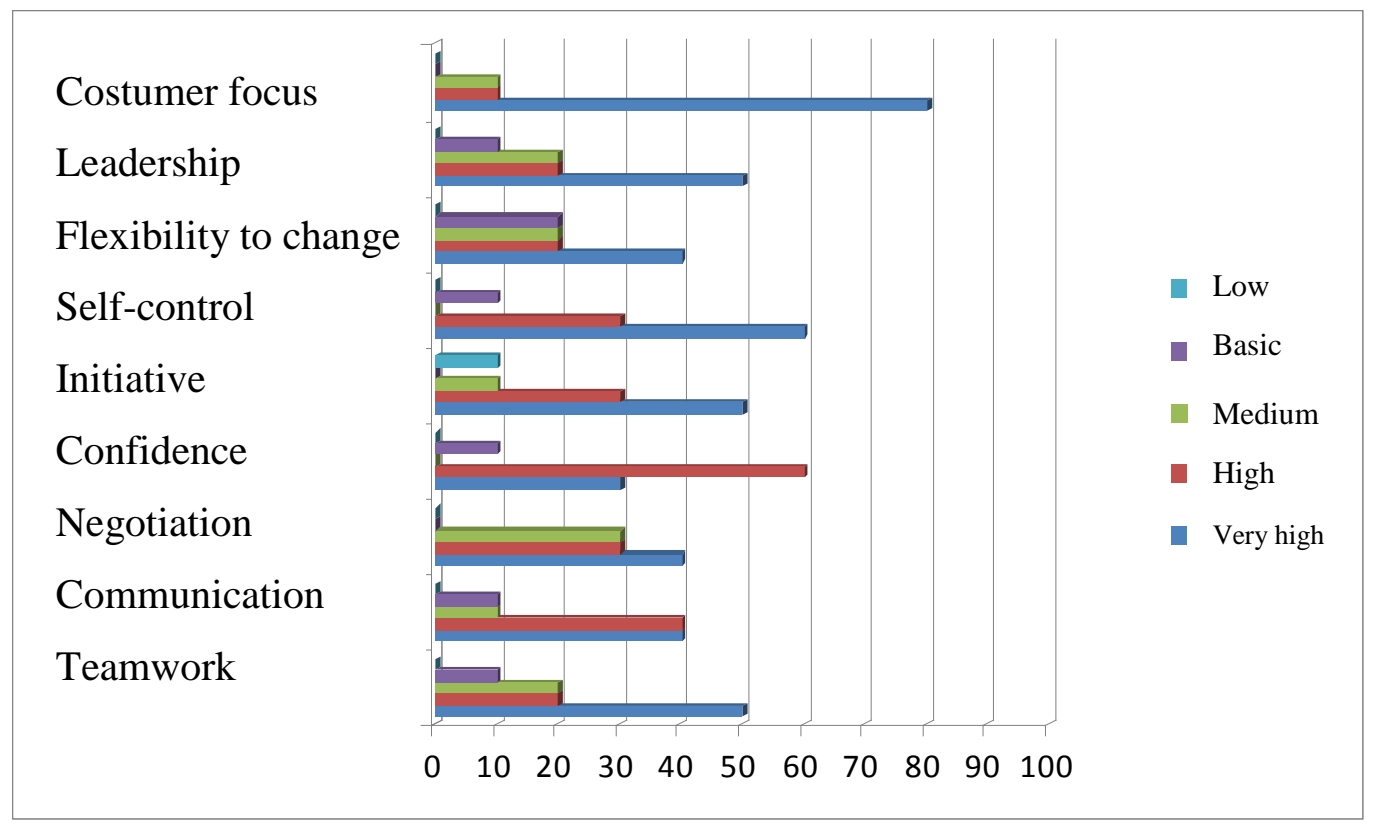

Figure 1. Transversal competencies assessment results

English skills (oral and written) were also evaluated, and over $60 \%$ of the students had a low or very low level of these skills.

\section{Conclusions}

Among the main achievements of this innovative project was the high students participation in the teaching activities and their high motivation towards the learning process. Student learning was more efficient because they have more resources to plan their activities, resulting in continuous dedication to the subject study. The high level of acceptance of the methodological resources by the students, and their acknowledge that it has served to improve not only their academic results but also the perceived learning level, lead to the conclusion that the experience can be considered as highly successful. This is supported as well by the fact that the level of involvement in virtual learning environments has clearly improved, both for new students in distance education and for students in the final year of the degree.

Regarding the transversal competencies, the results revealed that students have to improve their self-control, initiative and confidence skills. It is also important to highlight, that English communication skills, both oral and written, were also not satisfactory. 
All activities and recourses were applied as a source of on-going feedback with the aim to improve teaching and learning and consequently as a tool of formative assessment.

\section{References}

Dysthe, O., Engelsen, K.S. \& Lima, I. (2007). Variations in portfolio assessment in higher education: Discussion of quality issues based on a Norwegian survey across institutions and disciplines. Assessing Writing, 12, 129-148.

Gikandi, J.W., Morrow, D., \& Davis, N.E. (2011). Online formative assessment in higher education: A review of the literature. Computers \& Education, 57, 23332351.

Instituto de Ingeniería del Conocimiento. eValue. [http://www.iic.uam.es/pdf/eV.pdf]. Last access January 2015.

Instituto de Ingeniería del Conocimiento. eCat. http://www.iic.uam.es/pdf/eC.pdf. Last access January 2015.

Pachler, N., Daly, C., Mor, Y., \& Mellar, H. (2010). Formative e-assessment: Practitioner cases. Computers \& Education, 54, 715-721

Richey, R.C., Fields, D.C. \& Foxon, M. (2001). Instructional design competencies: the standards. Third edition. New York: Eric publication.

van der Wende, M.C. (2000). The Bologna Declaration: Enhancing the transparency and competitiveness of European Higher Education. Higher Education in Europe, 25, 305-310.

Wang, T.H., Wang, K.H., \& Huang, S.C. (2008). Designing a web-based assessment environment for improving pre-service teacher assessment literacy. Computers \& Education, 51, 448-462. 